\title{
Geographic Patterns of Innovation Across U.S. States: 1980-2010
}

Jesse LaBelle, Research Associate

Ana Maria Santacreu, Senior Economist

T he United States has steadily increased its pace of knowledge creation since the early 1980s, becoming one of the world leaders of innovation. A standard measure of innovation that academics, governments, and businesses use is the number of patents granted. By 2010, the number of new patents granted in the United States was almost three times larger than in $1980 .{ }^{1} \mathrm{~A}$ similar trend emerges when looking at new patents granted per 1,000 residents (Figure 1). While the United States has become more innovative overall, not all geographic areas have contributed equally to this upward trend. In this essay, we analyze state-level data on patents granted between 1980 and 2010 and document several features of the geographic distribution of U.S. innovation.

First, we find that the rate at which patents are granted is highly heterogeneous across U.S. states. Figure 2 shows the distribution of patent creation across U.S. states in the 1980s (left panel) and 2000s (right panel). Darker colors represent states where patents were created at a faster pace. In the 2000s, patent creation was concentrated mostly in three regions:
- Northeast: New York, New Jersey, Delaware, and the New England states

- West Coast: Oregon, Washington, Idaho, and California

- Rust Belt: Minnesota, Illinois, Michigan, Ohio, and Pennsylvania.

Together, these states accounted for about 67 percent of total patents granted in the 2000s.

While the East and West Coast states specialized in the computers and electronics sector, the Rust Belt states specialized in the machinery sector. These two sectors were the most innovative, based on the numbers of patents granted (Figure 3). ${ }^{2}$ The least innovative states were Mississippi, Arkansas, and Alaska. The rate of patent creation in the most innovative state was 22 times larger than in the least innovative state.

Second, the geographic distribution of innovation has evolved over time. A comparison between the left and right panels of Figure 2 shows that (i) innovation has become more concentrated over time and that (ii) the increased pace of patent creation has shifted to the West.

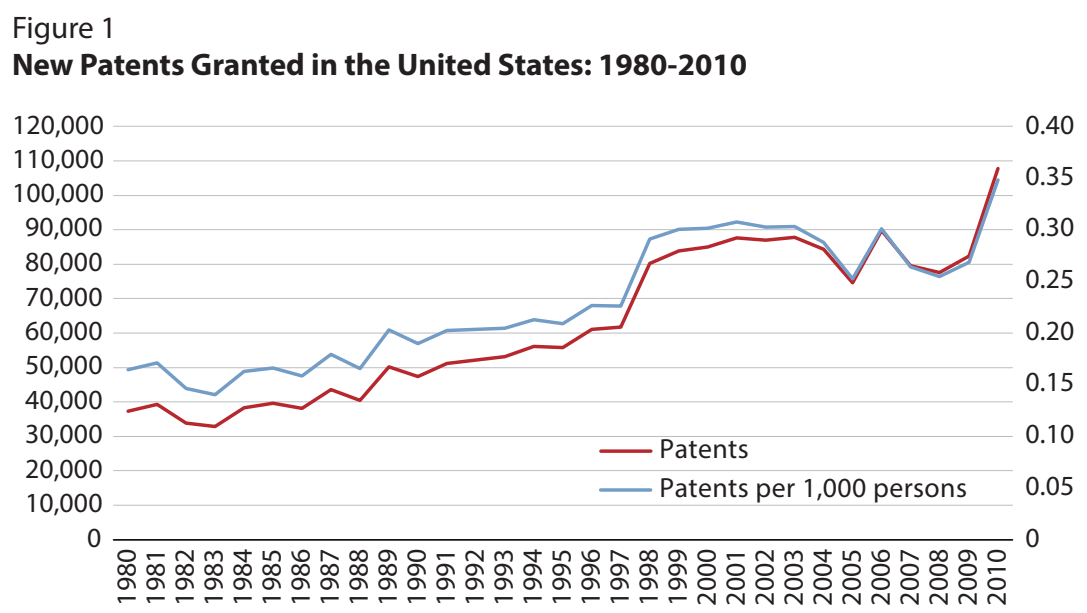

SOURCE: U.S. Patent and Trademark Office, Patent Technology Monitoring Team; Haver Analytics; and authors' calculations. 
Figure 2

New Patents Granted (per 1,000 persons): 1980s (left panel) and 2000s (right panel)

A. Patents per 1,000 persons by decade: 1980 s

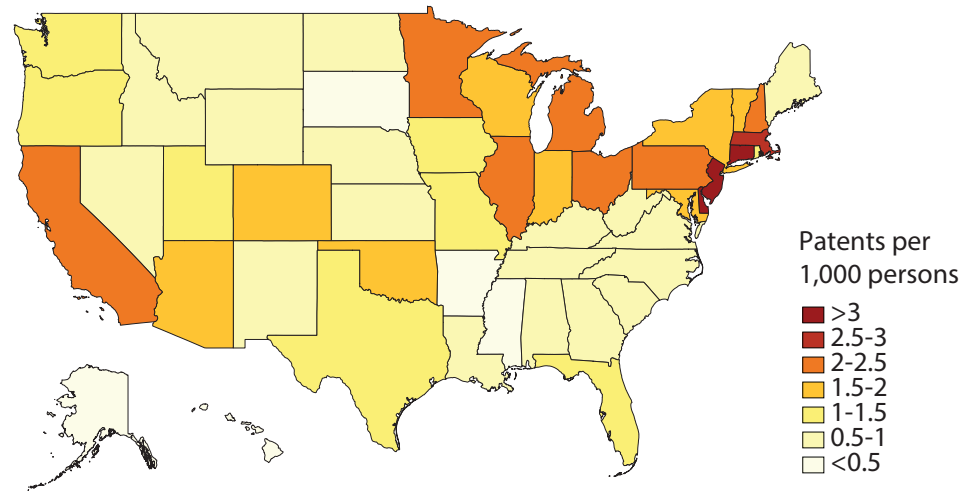

B. Patents per 1,000 persons by decade: 2000 s

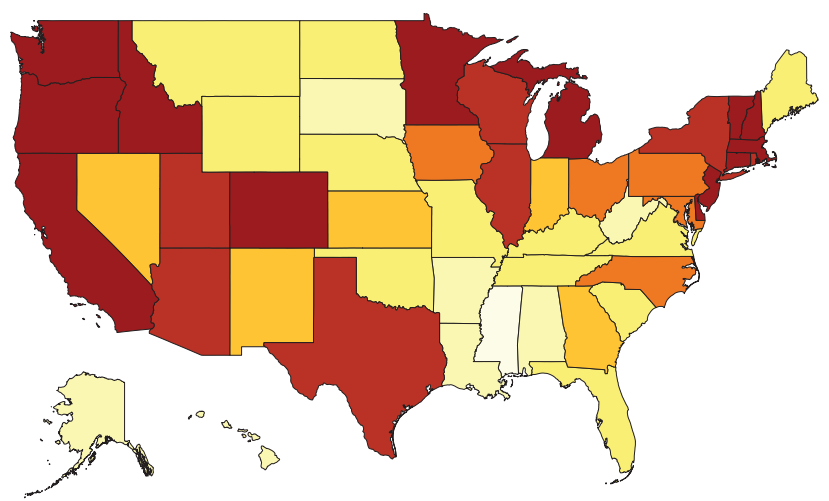

SOURCE: U.S. Patent and Trademark Office, Patent Technology Monitoring Team; Haver Analytics; and authors' calculations.

Figure 3

Number of Patents Granted by Sector: 1980s and 2000s

A. Patents granted by decade: 1980 s

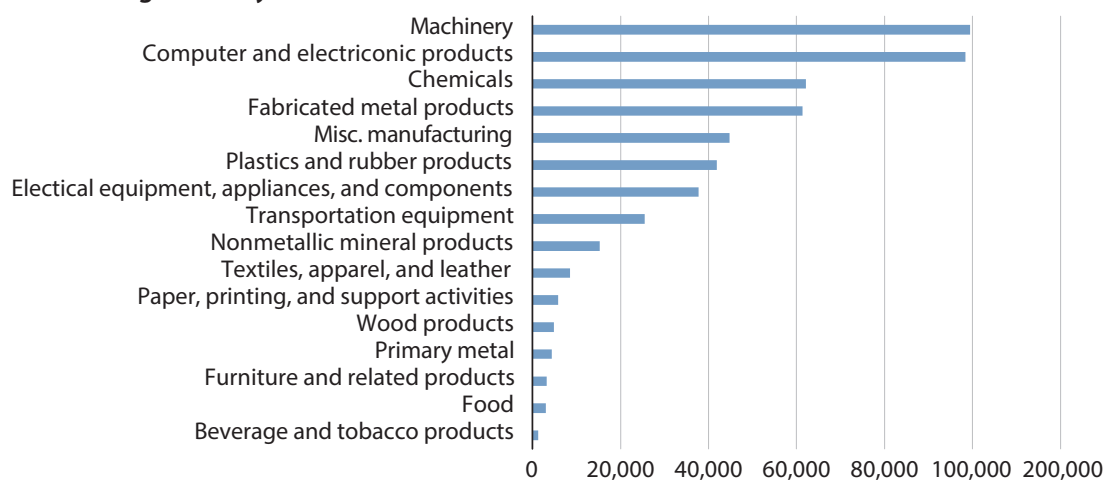

B. Patents granted by decade: 2000 s

Computer and electriconic products

Machinery

Chemicals

Misc. manufacturing

Electical equipment, appliances, and components

Fabricated metal products

Plastics and rubber products

Transportation equipment

Nonmetallic mineral products

Textiles, apparel, and leather

Paper, printing, and support activities

Wood products

Furniture and related products
Primary metal

Primary metal

Beverage and tobacco products

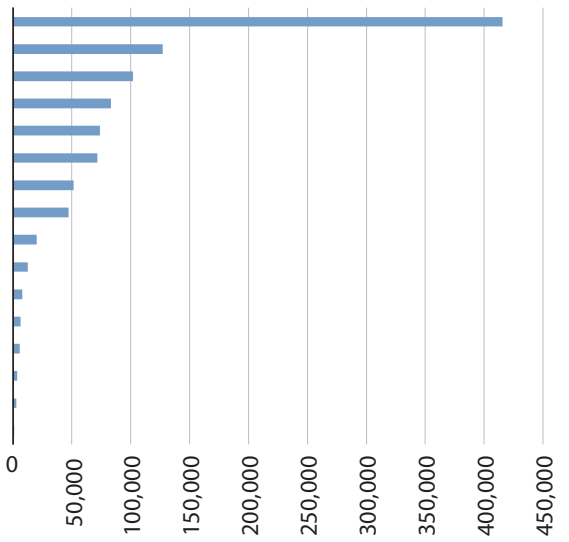

SOURCE: U.S. Patent and Trademark Office, Patent Technology Monitoring Team; Haver Analytics; and authors' calculations. 
The higher concentration is reflected by an increase in the cross-state standard deviation of new patents granted, from 0.95 in the 1980s to 1.97 in the 2000s. Knowledge tends to be created and then diffused through local proximity, which is why the economic activity in innovative sectors is likely to cluster geographically: The more recent geographic clustering of patent creation in the United States has been dominated by West Coast states. In the 1980s, the Rust Belt states dominated knowledge creation in the United States. (The darkest colors in the left panel of Figure 2 are in such states.) They accounted for over 26 percent of total patents granted in that decade. By the 2000s, they were replaced as innovation leaders by Western states. (The right panel of Figure 2 shows darker colors in several states along the West Coast.) Over this period, Western state patents went from an average of 1.4 per 1,000 persons to an average of 6.3 per 1,000 persons - an increase of 350 percent. These West Coast states accounted for over 30 percent of total patents granted in that decade. Meanwhile, the Rust Belt states went from averaging 2.2 patents per 1,000 persons to 3.2 patents per 1,000 persons-an increase of just 45 percent.

\section{The distribution of innovation in the United States has become more concentrated and has shifted to the West.}

These findings have interesting economic implications. First, the increase in geographic concentration and clustering of innovation suggests the presence of knowledge spillovers across U.S. states with innovation hubs, which is an important source of economic growth. ${ }^{3}$ Second, this westward geographic shift of innovation reflects the sectoral shift of innovation toward the computers and electronics sector. Also, future research could examine the geographic patterns of immigration overall and the high share of immigrants with engineering and science degrees employed in this sector. ${ }^{4}$

\begin{abstract}
Notes
1 Our measure of innovation is the number of new utility patents (of U.S. origin) granted in the United States. Source: U.S. Patent and Trademark Office, Patent Technology Monitoring Team.

2 Bins in Figure 3 are chosen as seven equally spaced stationary levels, consistent with the 1980 distribution, to best showcase growth across the period.

3 See Cai, Li, and Santacreu (forthcoming in American Economic Journal: Macroeconomics).

${ }^{4}$ In a recent study, Burchardi et al. (2020) find a causal impact of immigration on local innovation and several measures of economic activity.
\end{abstract}

\section{References}

Burchardi, K.B.; Chaney, T.; Hassan, T.A.; Tarquinio, L. and Terry, S.J. "Immigration, Innovation, and Growth." Working Paper No. w27075, National Bureau of Economic Research, 2020; https://doi.org/10.3386/w27075.

Cai, J.; Li, N. and Santacreu, A. "Knowledge Diffusion, Innovation and Trade Across Countries and Sectors." American Economic Journal: Macroeconomics (forthcoming). 